\title{
Influência das esquadrias e da geometria do ambiente no desempenho acústico de vedações verticais em edifícios
}

\author{
Influence of environmental frames and geometry on the acoustic performance of vertical \\ partitions in buildings
}

\section{Pedro Henrique Rosa de Souza ${ }^{1}$ (iD) https://orcid.org/0000-0002-5645-6985}

Fábia Kamilly Gomes de Andrade ${ }^{2}$ (D) https://orcid.org/0000-0001-5452-8992

\author{
Alberto Casado Lordsleem Júnior ${ }^{3}$ (B) https://orcid.org/0000-0003-3276-0621 \\ ${ }_{1}^{1}$ POLITECH - Escola Politécnica de Pernambuco, Universidade de Pernambuco, Recife, Brasil, \\ 2 MSc., POLITECH - Escola Politécnica de Pernambuco, Universidade de Pernambuco, Recife, Brasil, \\ ${ }^{3}$ Pós DSc., Coordenador do POLITECH - Escola Politécnica de Pernambuco, Universidade de Pernambuco, Recife, Brasil. \\ E-mail do autor principal: Pedro Henrique Rosa de Souza phrs110@gmail.com \\ Resumo
}

A excessiva exposição aos ruídos é um problema das metrópoles brasileiras. Seus efeitos podem afligir a saúde do indivíduo. A transmissão sonora aos ambientes internos de edifícios deve, portanto, ser prevista em projeto para que ocorra adequadamente. O presente artigo objetiva investigar a conformidade do desempenho acústico obtido por vedações verticais em edifícios habitacionais localizados no Recife e analisar a influência das esquadrias utilizadas e da geometria dos ambientes analisados. Para tal, avaliou-se o desempenho acústico de vedações verticais internas e externas de 7 edifícios residenciais da cidade, por ensaio de procedimento preconizado pela norma NBR 15575 (ABNT, 2013) e compilou-se os dados no software dBBati, os quais foram analisados em relação aos fatores indicados. $13 \%$ das vedações internas analisadas apresentou isolamento em conformidade com a normalização. Nenhuma das vedações externas avaliadas apresentou resultado satisfatório. Observou-se uma relação dos menores tempos de reverberação com cômodos de volumes de valor intermediário.

Palavras-Chave: Isolamento acústico; Vedação vertical; Desempenho;

\section{Abstract}

Excessive exposure to noise is a problem of Brazilian metropolises. Its effects can afflict the individual health. Therefore, sound transmission to indoor environments of buildings should be predicted in design to occur properly. This article aims to investigate the acoustic performance achieved by vertical fences in residential buildings located in Recife and to analyze the influence of the frames used and the geometry of the analyzed environments. The acoustic performance of internal and external vertical seals of 7 residential buildings in the city was evaluated by a procedure test recommended by NBR 15575 (ABNT, 2013) and the data were compiled in dBBati software, which were analyzed in relation to the indicated factors. $13 \%$ of the internal seals analyzed presented isolation in accordance with normalization. None of the evaluated external fences presented satisfactory results. It was observed a relation of the smaller reverberation times with rooms of intermediate value volumes.

Key-words: Acoustic insulation; Vertical partition; Performance. 


\section{Introdução}

A abertura de crédito aos consumidores e produtores que, segundo Mattei [1], ocorreu no Brasil entre 2006 e 2012, promoveu crescimentos no PIB nacional até 2014, como discorrem Cury e Caoli [2]. Esse processo ocasionou o crescimento dos centros urbanos brasileiros e aumentou a exposição de seus habitantes - o que, segundo o Censo 2010 , corresponde a $25,4 \%$ da população do país - a ruídos e poluição sonora em níveis excessivos. O ruído é uma mistura de sons indesejáveis, uma oscilação aleatória, segundo a NBR 12179 [3].

Com a nova situação econômica do país, elucidada por Fraga [4], a indústria da construção civil encontra-se numa posição de menos privilégios. No momento atual, seu desafio em proporcionar boa qualidade em seus serviços se torna mais pujante, para que assim se obtenha maior aceitação de um mercado cujo perfil de usuário está mais exigente na avaliação de atributos de uma edificação para a compra de um imóvel.

A garantia dessa vantagem competitiva de forma sustentável se dá fundamentalmente por meio do desenvolvimento de atributos tecnológicos por parte das empresas, de acordo com Zhou e Wu [5]. Isso sugere a necessidade das construtoras em aprimorar seus serviços, a fim de atingir o desempenho requerido para cada uma das propriedades das obras a serem construídas, e também em produzir edificações que atendam às novas demandas das cidades brasileiras, inclusive no tocante ao isolamento acústico.

Vale elucidar que evitar a transmissão do ruído em limites acima do ideal vai para além da promoção de agradabilidade num ambiente. Com este tipo de preocupação no projeto e execução de um edifício, contribui-se para a prevenção de problemas não só de ordem psíquica, como também disfunções gastrointestinais, vasculares, respiratórias, hormonais e nervosas $[6,7,8]$ que podem ocorrer num indivíduo exposto à poluição sonora.

A norma NBR 15575 [9] é uma das grandes e mais recentes ferramentas para o incremento tecnológico das habitações. Por meio do estabelecimento de requisitos e critérios de desempenho, ela garante 0 atendimento às necessidades do consumidor e maior valorização comercial às edificações $[10,11]$. A parte 4 da NBR 15575 trata dos requisitos para os sistemas de vedações verticais internas e externas e possui seção dedicada ao desempenho acústico.

Segundo Penedo e Oiticica [12], os requisitos acústicos são características específicas que possibilitam a análise do desempenho dos ambientes. Eles podem ser medidos por meio de ensaios indicados pela norma de desempenho [9].

Diante desse contexto, 0 presente trabalho objetiva analisar a conformidade do desempenho acústico obtido por vedações verticais em edifícios habitacionais com os critérios determinados pela norma brasileira NBR 15575 [9], além de relacionar estes resultados com detalhamentos construtivos da vedação relativos à relação entre área das esquadrias e da parede na qual estão instaladas, bem como ao volume dos ambientes analisados.

\section{A importância dos elementos da vedação vertical no desempenho acústico}

As vedações verticais são o subsistema do edifício que limita, define e compartimenta a edificação, de acordo com Lordsleem Júnior e Marques $[13,14]$ e contribui para que se desenvolvam adequadamente as atividades para as quais foram projetadas. Elas são as responsáveis pela delimitação dos ambientes internos e pela proteção contra agentes indesejáveis, inclusive o ruído, como elucidado por Medeiros [15].

Seus elementos constituintes são o vedo, que caracteriza a vedação vertical, a esquadria, que permite o controle de acesso aos ambientes, e o revestimento, que possibilita o acabamento da vedação [13]. A variedade de soluções constituintes dos elementos pode resultar em diferenças consideráveis no desempenho acústico, em especial nos fechamentos criados pelos vedos, segundo Shvarstzhahaupt, Tutikian e Nunes [16].

Esse efeito pode ser atenuado ou revertido por meio do aperfeiçoamento de materiais construtivos a serem utilizados nos vedos, como sugere Santos Neto et al. [17], com a utilização de fibra residual do setor sucroalcooleiro como enchimento alternativo para drywall. Essa adição criou um 
sistema do tipo massa-mola-massa, que, segundo Carvalho, confere ao ambiente considerável capacidade de isolamento acústico [6].

As esquadrias são elementos de grande variedade de formas e dimensões. Bastante diverso também é o posicionamento das mesmas em relação à parede. A madeira, o alumínio e o PVC são materiais comumente utilizados na sua fabricação. Segundo Beltrame [18], janelas de correr integradas com vidro de $6 \mathrm{~mm}$ de espessura obtiveram o desempenho acústico mais satisfatório. Também foram avaliadas esquadrias da tipologia indicada com vidro de $4 \mathrm{~mm}$ de espessura, além de venezianas e janelas de correr simples com ambas as espessuras.

O tipo de vidro a ser empregado, bem como a adição de acessórios à esquadria, também influenciam no desempenho acústico da mesma, como explanado por Schvarstzhaupt, Tutikian e Nunes [16], ao constatarem que o uso de persianas favorece no isolamento sonoro do componente, especialmente em esquadrias de vidro simples, as quais não ofereceram tão boa eficiência no desempenho acústico quanto as de vidro laminado, como indicado na avaliação realizada pelos autores.

Segundo Jones [19], não só a esquadria em si influencia na transmissão sonora, como também o seu sistema de vedação. O autor sugere a aplicação de materiais que promovam fechamento das fendas das portas, as quais devem ser fabricadas com materiais que funcionem como um sistema massamola-massa.

Outra solução indicada é o uso de dobradiças de levantamento, que promovem o abaixamento da porta no momento em que ela é fechada. Carvalho

\section{0 desempenho acústico segundo a norma NBR 15575}

A norma de desempenho traz 3 parâmetros acústicos relativos as vedações verticais, dos quais 2 foram utilizados no presente trabalho: a diferença padronizada de nível ponderada $\left(D_{n T}, w\right)$ e a diferença padronizada de nível ponderada a $2 \mathrm{~m}$ de distância da fachada (D2m,nT,w), presentes na ISO 140-4 e ISO $140-5[22,23]$, respectivamente.

$\mathrm{O} \mathrm{DnT}, \mathrm{w}$ mede o isolamento acústico promovido por vedação interna em edificação e o $\mathrm{D} 2 \mathrm{~m}, \mathrm{nT}, \mathrm{w}$ indica o isolamento acústico promovido por fachadas de edifícios e sobrados. Esses parâmetros podem ser medidos em 2 dos 3 métodos de avaliação indicados na norma: o de engenharia, utilizado no trabalho,
[6] também mostra preocupação com a vedação da porta em relação ao piso ao propor a adoção de chanfros vedados na região da soleira.

Também é citado por Jones [19] que a contribuição de uma janela ao desempenho acústico de um ambiente depende do cuidado com a qual foi instalada e da área relativa entre o elemento e a parede na qual a mesma foi instalada, além da perda de transmissão sonora por parte da janela isoladamente.

Carvalho [6] salienta a importância de se aplicar material absorvente nas conexões dos vidros com as esquadrias e de se escolher a forma de fechamento das mesmas. Também é citada por este autor a hipótese de criação de vácuo entre cada duas lâminas de vidro.

A escolha da geometria do ambiente adequada ao seu uso é indicada por Mateus [20] como uma alternativa à busca pela otimização do tempo de reverberação no mesmo, o que depende da aplicação de volumes próprios para a sua destinação, como cita Carvalho [6]. Além dessa propriedade, um ambiente de bom desempenho acústico possui ruído de fundo minimizado, além de som bem distribuído e inteligível em seu interior [20].

Outra advertência trazida pelo autor é a potencialidade de ocorrência de ecos em ambientes de paredes opostas muito distantes. Fauro, Rocha e Pereira [21] acrescentam que em superfícies muito próximas e paralelas, há suscetibilidade à ocorrência do fenômeno. Essa configuração em planta é bastante presente em cômodos de apartamentos em edifícios

habitacionais.

que caracteriza de forma direta o comportamento acústico do sistema de vedações como um todo, e o método simplificado, que permite obter valores estimados de isolamento sonoro de fechamentos internos e externos, em situações onde não se dispõe de aparelhos ou condições de ruído necessárias para realização do procedimento convencional. Segundo a ABNT [9], o método de engenharia, dentre os de campo, é o mais preciso e, portanto, foi o utilizado no presente trabalho.

Além desses experimentos, a norma traz o método de precisão, realizado em laboratório, que ensaia a isolação sonora de componentes e elementos construtivos separadamente. 
A norma NBR 15575 [9] estabelece os critérios mínimos a serem avaliados por meio de algum dos métodos acima citados. O D2m,nT,w possui limites inferiores associados ao entorno da obra, que foi categorizado em classes de ruído, como segue no Quadro 1. Ele deve ser medido nos dormitórios da unidade habitacional, com as portas e janelas fechadas.

Quadro 1: Valores mínimos de D2m,nT,w. Fonte: ABNT, 2013

\begin{tabular}{|l|l|l|}
\hline \multicolumn{2}{|c|}{$\begin{array}{c}\text { Classe de } \\
\text { ruído }\end{array}$} & $\geq 20$ \\
\hline I & $\begin{array}{l}\text { Habitação localizada distante de } \\
\text { fontes de ruído intenso de } \\
\text { quaisquer naturezas. }\end{array}$ \\
\hline II & $\begin{array}{l}\text { Habitação localizada em áreas } \\
\text { sujeitas a situações de ruído não } \\
\text { enquadráveis nas classes I e III }\end{array}$ & $\geq 25$ \\
\hline III & $\begin{array}{l}\text { Habitação sujeita a ruído intenso } \\
\text { de outras naturezas, desde que } \\
\text { conforme a legislação. }\end{array}$ & $\geq 30$ \\
\hline
\end{tabular}

A norma carece de indicações para vedação externa de salas, cozinhas, lavanderias e banheiros. Nela indica-se a necessidade de realização de estudos específicos no caso do empreendimento ser localizado em regiões próximas de equipamentos urbanos de emissão sonora de grande magnitude, como aeroportos, estádios, locais de eventos esportivos, rodovias e ferrovias.

São também estabelecidos critérios mínimos para o DnT,w, os quais diferem de acordo com o ambiente de análise. A seguir, o Quadro 2 indica valores mínimos do DnT,w a serem obtidos na edificação.
Quadro 2: Valores mínimos de DnT,w entre ambientes. Fonte: ABNT, 2013

\begin{tabular}{|c|c|}
\hline Elemento & $\begin{array}{c}\text { DnT,w } \\
\text { (dB) }\end{array}$ \\
\hline $\begin{array}{l}\text { Parede entre unidades habitacionais autônomas } \\
\text { (parede de geminação), nas situações onde não haja } \\
\text { ambiente dormitório }\end{array}$ & $\geq 40$ \\
\hline $\begin{array}{c}\text { Parede entre unidades habitacionais autônomas } \\
\text { (parede de geminação), caso pelo menos um dos } \\
\text { ambientes seja dormitório }\end{array}$ & $\geq 45$ \\
\hline $\begin{array}{l}\text { Parede cega de dormitórios entre uma unidade } \\
\text { habitacional e áreas comuns de trânsito eventual, } \\
\text { como corredores e escadaria nos pavimentos }\end{array}$ & $\geq 40$ \\
\hline $\begin{array}{l}\text { Parede cega de salas e cozinhas entre uma unidade } \\
\text { habitacional e áreas comuns de trânsito eventual } \\
\text { como corredores e escadaria dos pavimentos }\end{array}$ & $\geq 30$ \\
\hline $\begin{array}{c}\text { Parede cega entre uma unidade habitacional e áreas } \\
\text { comuns de permanência de pessoas, atividades de } \\
\text { lazer e atividades esportivas, como home theater, } \\
\text { salas de ginástica, salão de festas, salão de jogos, } \\
\text { banheiros e vestiários coletivos, cozinhas e } \\
\text { lavanderias coletivas }\end{array}$ & $\geq 45$ \\
\hline $\begin{array}{c}\text { Conjunto de paredes e portas de unidades distintas } \\
\text { separadas pelo hall (DnT,w obtida entre as } \\
\text { unidades). }\end{array}$ & $\geq 40$ \\
\hline
\end{tabular}

Os isolamentos indicados pelos parâmetros citados acima ocorrem por meio da interação entre o ruído e as vedações da edificação, a qual, segundo Martins [8], dá-se por meio dos fenômenos de absorção, reflexão ou transmissão.

\section{Método}

\subsection{Caracterização do objeto de estudo}

O presente estudo analisou 7 edifícios habitacionais multifamiliares. Todas as vedações estavam finalizadas e, portanto, todos os seus elementos constituintes estavam instalados, o que é necessário para a correta realização do procedimento de ensaio.

Os empreendimentos localizam-se na cidade do Recife. Seus pavimentos tipo são definidos por plantas baixas de tipologias diversas. Igualmente variados são os zoneamentos nos quais os edifícios se localizam, de acordo com o preconizado na NBR 15575 [9] e com o avaliado pelos autores, como pode ser observado no Quadro 3.

As unidades habitacionais estudadas ainda não estavam em fase de operação e, portanto, os espaços foram avaliados vazios. No total, foram analisadas 23 vedações internas e 13 vedações externas.

As esquadrias instaladas nas obras em análise são todas em alumínio, com escova de polipropileno nas áreas de flancos, e possuem vidro comum de $4 \mathrm{~mm}$ de espessura. Todas operam em abertura de correr. Uma das vedações analisadas na obra B possui uma parte fixa e a observada na obra $C$ tem formato de $L$. As áreas variam entre 1,3 e $2,1 \mathrm{~m}^{2}$. 
Quadro 3: Caracterização dos empreendimentos estudados. Fonte: Os autores

\begin{tabular}{|c|c|c|c|c|c|c|}
\hline Obra & Bairro & \multicolumn{1}{c}{ Torres } & \multicolumn{1}{c}{$\begin{array}{c}\text { Pavimentos } \\
\text { tipo }\end{array}$} & $\begin{array}{c}\text { Unidades } \\
\text { por } \\
\text { pavimento }\end{array}$ & $\begin{array}{c}\text { Quartos por } \\
\text { unidade }\end{array}$ & $\begin{array}{c}\text { Área } \\
\text { privativa } \\
\text { (m2) }\end{array}$ \\
\hline A & Madalena & 1 & 29 & 2 & 4 & 153 \\
\hline B & Boa Vista & 1 & 29 & 4 & 3 & 69 e 76 \\
\hline C & Rosarinho & 1 & 20 & 2 & 3 & 108 \\
\hline D & Poço da Panela & 2 & 7 & 4 & 3 & 108 \\
\hline E & Arruda & 1 & 17 & 6 & 3 & 58,38 \\
\hline F & Boa Vista & 1 & 20 & 12 & 1 e 2 & 38 e 52 \\
\hline G & Torre & 1 & 28 & 4 & 2 e 3 & 51,32 e 62,82 \\
\hline
\end{tabular}

\subsection{Os equipamentos de medição e outras ferramentas}

As etiquetas das figuras devem ser legíveis, aproximadamente de 8 a 10 pontos, quando reduzidas à largura da coluna do artigo. Os equipamentos de medição usados em campo na pesquisa constam de um decibelímetro, uma fonte emissora de ruído dodecaédrica omnidirecional e um calibrador. Para a compilação dos dados obtidos nos experimentos, utilizou-se os softwares dBBati e Excel. As funções de cada um dos equipamentos anteriormente citados estão elencadas no Quadro 4.

Quadro 4: Equipamentos e ferramentas utilizados nos experimentos. Fonte: Os autores

\begin{tabular}{|c|l|}
\hline Decibelímetro & $\begin{array}{l}\text { Medidor de nível de pressão sonora. } \\
\text { Coleta os ruídos de emissão, recepção } \\
\text { e os tempos de reverberação no } \\
\text { experimento. }\end{array}$ \\
\hline Calibrador acústico & $\begin{array}{l}\text { Verifica a calibração do medidor, } \\
\text { conforme as especificações do } \\
\text { fabricante. }\end{array}$ \\
\hline $\begin{array}{c}\text { Fonte emissora de } \\
\text { ruído }\end{array}$ & $\begin{array}{l}\text { Composta por } 1 \text { haste elevatória, 1 } \\
\text { amplificador de potência, 1 fonte } \\
\text { sonora dodecaédrica e 1 controle } \\
\text { remoto. Responsável pela criação de } \\
\text { condição acústica no ambiente } \\
\text { favorável à realização do experimento. }\end{array}$ \\
\hline Software dBBati & $\begin{array}{l}\text { Software responsável pela compilação } \\
\text { dos dados de campo e geração dos } \\
\text { resultados. }\end{array}$ \\
\hline Software Excel & $\begin{array}{l}\text { Software utilizado para documentação } \\
\text { e análise dos dados compilados. }\end{array}$ \\
\hline
\end{tabular}

\subsection{Coleta e compilação de dados}

Os experimentos foram realizados segundo o método de engenharia recomendado pela norma NBR 15575 [9], a qual indica, para o sistema de vedações verticais externas (fachadas), o procedimento descrito na norma ISO 140-5 [23], bem como para o sistema de vedações verticais internas, o descrito na ISO 140-4 [22].

Ressalta-se a substituição dessas 2 normas pela ISO 16283-1 [24], sendo assim levada em consideração a mais recente. Nela, é indicado que a fonte sonora deve ser colocada no centro da sala, que o medidor e qualquer superfície não devem estar distanciados a menos que $0,5 \mathrm{~m}$, sendo que os pontos de leitura do medidor devem estar preferencialmente sem alinhamento e distantes de, no mínimo, 0,7 m entre si, que a distância entre o piso e o medidor deve ser maior ou igual $1,2 \mathrm{~m}$ e que, entre 0 medidor e a fonte sonora, deve ser maior ou igual a $1,0 \mathrm{~m}$.

Figura 1: Realização do ensaio. Fonte: Os autores

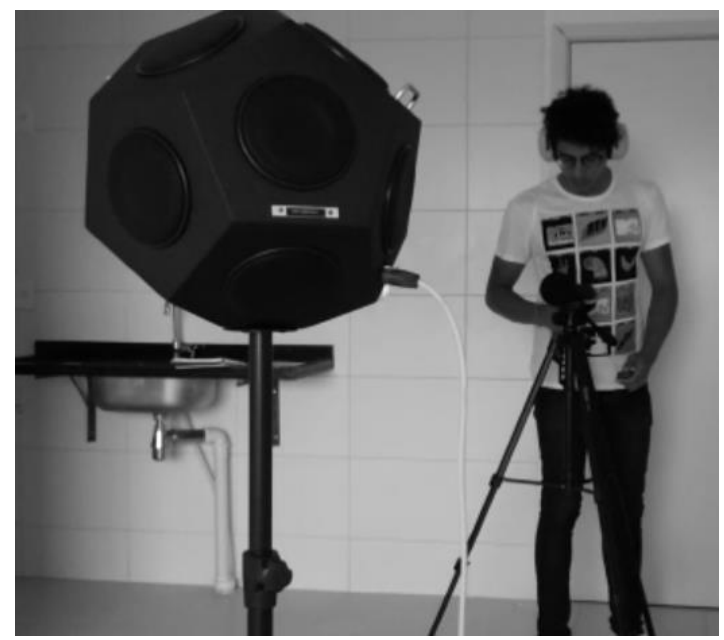

A intensidade das ondas sonoras emitidas pela fonte foi mantida elevada o suficiente para que, juntamente com o ruído de fundo, atingisse $110 \mathrm{~dB}$. Isso garante uma diferença de, pelo menos $10 \mathrm{~dB}$ entre 0 ruído de fundo e o de recepção, como recomenda a norma ISO 16283-1 [24], conferindo eficiência à compilação de dados por parte do

http://dx.doi.org/10.25286/repa.v4i1.923 
software dBBati, o qual exige uma diferença mínima de $6 \mathrm{~dB}$ entre os mesmos ruídos.

\section{Resultados}

\subsection{Avaliação da conformidade acústica}

Foram analisadas 23 vedações internas, indicadas na Tabela 1 pelo índice $\mathrm{I}$, o que confere 69 resultados de $\mathrm{DnT}, \mathrm{w}$ em $\mathrm{dB}$, dos quais 3 estão indicados por asterisco por não terem sido compilados pelo software dBBati, visto que a diferença entre o ruído de fundo e o de recepção foi menor que $6 \mathrm{~dB}$. Os valores mínimos obtidos em cada vedação está indicado em negrito.

\begin{tabular}{|c|c|c|c|c|c|}
\hline \multirow{2}{*}{ Obra } & \multirow{2}{*}{$\begin{array}{c}\text { Classe } \\
\text { de } \\
\text { ruído }\end{array}$} & \multirow{2}{*}{ Vedação } & \multicolumn{3}{|c|}{$D_{2 m, n T, w}(d B)$} \\
\hline & & & Leitura 1 & Leitura 2 & Leitura 3 \\
\hline A & II & E1 & 23 & 23 & 23 \\
\hline \multirow{2}{*}{ B } & \multirow{2}{*}{ III } & E2 & 21 & 21 & 20 \\
\hline & & E3 & 23 & 23 & 23 \\
\hline C & II & E4 & 20 & 19 & 20 \\
\hline \multirow{3}{*}{ D } & \multirow{3}{*}{ II } & E5 & 21 & 21 & 21 \\
\hline & & E6 & 20 & 21 & 21 \\
\hline & & E7 & 24 & 24 & 24 \\
\hline \multirow{2}{*}{$\mathrm{E}$} & \multirow{2}{*}{ III } & E8 & 19 & 19 & 19 \\
\hline & & E9 & 19 & 19 & 19 \\
\hline \multirow{2}{*}{$\mathrm{F}$} & \multirow{2}{*}{ III } & E10 & 23 & 22 & 23 \\
\hline & & E11 & 22 & 22 & 22 \\
\hline \multirow{2}{*}{ G } & \multirow{2}{*}{ II } & E12 & 18 & 18 & 18 \\
\hline & & E13 & 19 & 20 & 21 \\
\hline
\end{tabular}

Tabela 1: Resultados de DnT,w em vedações internas. Fonte: Os autores

\begin{tabular}{l|l|l|l|l}
\hline \multirow{2}{*}{ Obra } & \multirow{2}{*}{ Vedação } & \multicolumn{3}{|c}{$\mathrm{D}_{\mathrm{nT}, \mathrm{w}}$ (dB) } \\
\cline { 3 - 5 } & & $\begin{array}{c}\text { Leitura } \\
\mathbf{1}\end{array}$ & Leitura 2 & Leitura 3 \\
\hline \multirow{3}{*}{ A } & I1 & $\mathbf{3 8}$ & $*$ & $\mathbf{3 8}$ \\
\cline { 2 - 5 } & I2 & $\mathbf{3 9}$ & 40 & 40 \\
\cline { 2 - 5 } & I3 & $\mathbf{4 0}$ & $\mathbf{4 0}$ & $\mathbf{4 0}$ \\
\hline \multirow{2}{*}{ B } & I4 & $\mathbf{3 9}$ & $\mathbf{3 9}$ & 40 \\
\hline
\end{tabular}

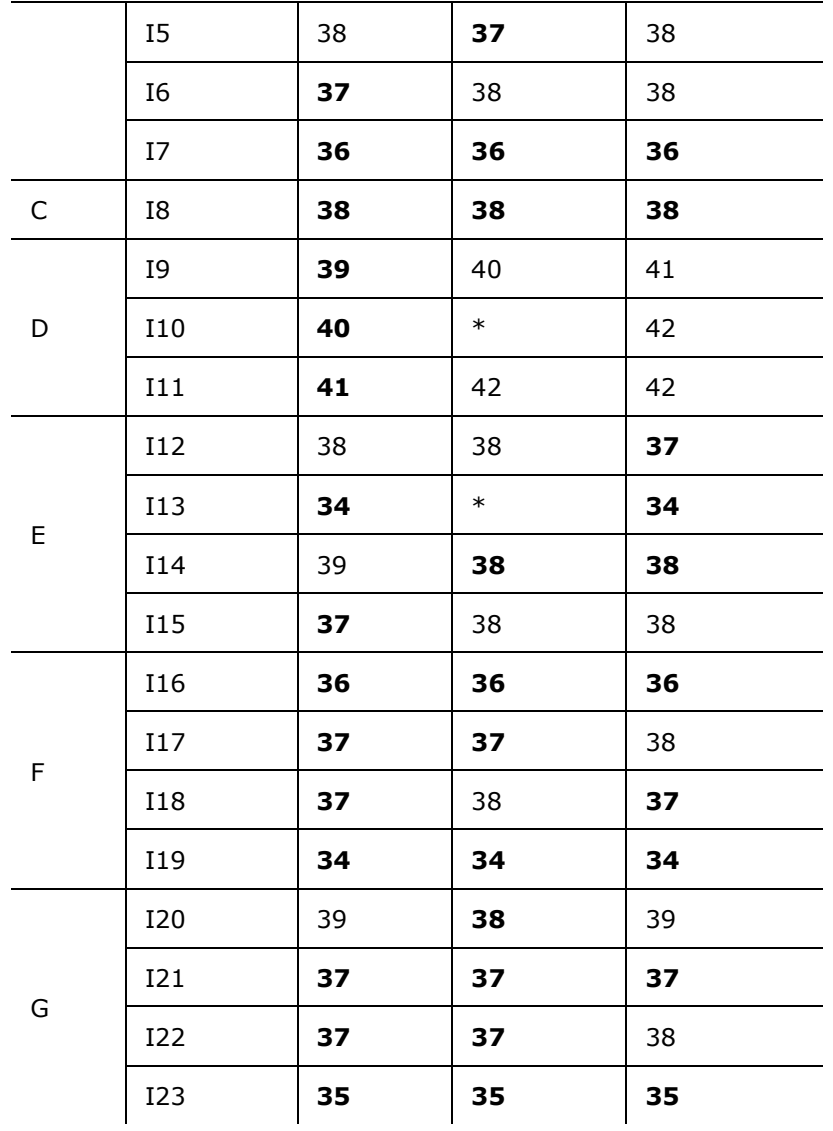

Tabela 2: Resultados de $\mathrm{D} 2 \mathrm{~m}, \mathrm{nT}, \mathrm{w}$ em vedações externas. Fonte: Os autores.

Da mesma forma, segue na Tabela 2 os 39 resultados decorrentes das 13 vedações externas avaliadas. Nela também estão expressas as classes de ruído para cada uma das obras, a fim de servir como base para análise do desempenho de cada uma das vedações.

Levando-se em consideração os dados acima citados, pôde-se constatar que, entre as vedações internas, apenas 13,04\% apresentaram conformidade com as recomendações da norma de desempenho, como indica a figura 1 . Nenhuma das vedações externas obteve resultados satisfatórios quanto à adequação do $\mathrm{D} 2 \mathrm{~m}, \mathrm{nT}, \mathrm{w}$ em relação à classe de ruído na qual o ambiente das mesmas foi categorizado. 
Figura 1: Conformidade de vedações internas com a NBR 15575 (ABNT, 2013). Fonte: Os autores.

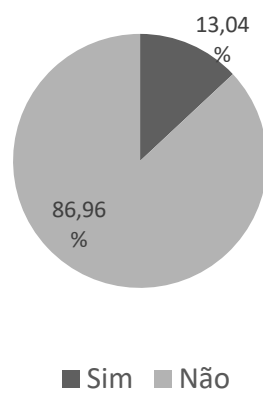

O menor déficit de desempenho acústico foi observado na vedação E7 e o maior, nas vedações E8 e E9, as quais não manifestaram resultado adequado a vedação externa presente em ambiente de qualquer classe de ruído. O isolamento realizado pelas mesmas representa pouco menos de $2 / 3$ do necessário a ser atingido, como pode ser inferido da tabela (3).

Tabela 3: Valores deficitários de D2m, nT, w dentre as vedações externas em análise. Fonte: Os autores.

\subsection{Avaliação da conformidade acústica}

A seguir, apresenta-se a relação entre os volumes dos ambientes de recepção com o desempenho acústico obtido pelas vedações internas analisadas.

Algumas das vedações estão contidas em ambientes de mesmo volume; nesse caso, a análise foi realizada com $o$ valor médio do isolamento obtido entre os valores mínimos das leituras do DnT,w de vedações presentes nesses ambientes.

A figura 2 indica que volumes maiores garantem melhor desempenho acústico. No entanto, o contrário não foi observado: os menores desempenhos estão relacionados a volumes de valor intermediário.

Figura 2: Desempenho acústico das vedações internas em relação ao volume dos ambientes de recepção. Fonte: Os autores.

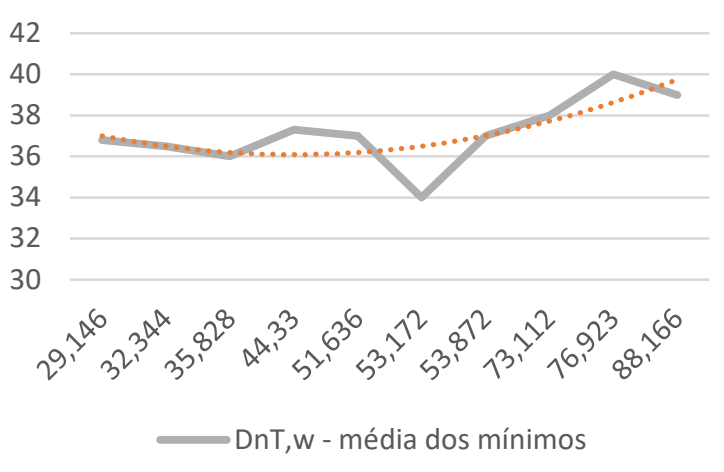

A mesma tendência foi obtida com a relação entre os volumes dos ambientes avaliados e os respectivos tempos de reverberação (ou TR60) máximos encontrados, como indicado na figura 3, o que aponta para a existência de volumes ótimos para a minimização dos tempos de reverberação no ambiente.

Figura 3: Tempos de reverberação em relação aos volumes dos ambientes de recepção. Fonte: Os autores.

\begin{tabular}{|c|l|l|l|l}
\cline { 2 - 5 } \multicolumn{1}{c|}{} & Esquadria & $\begin{array}{c}\mathrm{D}_{2 \mathrm{~m}, \mathrm{nT}, \mathrm{w}} \\
(\mathrm{dB})\end{array}$ & $\begin{array}{c}\text { Classe } \\
\mathrm{de} \\
\text { ruído }\end{array}$ & $\begin{array}{c}\text { Decréscimo } \\
(\mathrm{dB})\end{array}$ \\
\hline $\begin{array}{c}\text { Melhor } \\
\text { Desempenho }\end{array}$ & $\mathrm{E} 7$ & 24 & II & -1 \\
\hline $\begin{array}{c}\text { Pior } \\
\text { Desempenho }\end{array}$ & $\mathrm{E} 8, \mathrm{E} 9$ & 19 & III & -11 \\
\hline
\end{tabular}

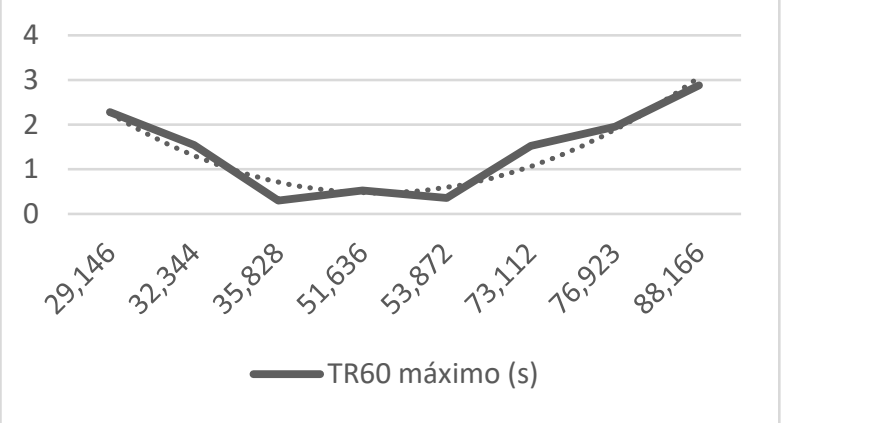

Os valores de $\mathrm{D} 2 \mathrm{~m}, \mathrm{nT}, \mathrm{w}$ foram relacionados à razão entre a área da esquadria e a área da parede na qual a mesma foi inserida, ambas presentes em cada uma das vedações respectivamente analisadas.

A figura 4 indica a oscilação encontrada nos resultados, visto que os menores desempenhos se encontram não só associados aos valores extremos, como também aos intermediários da relação. No entanto, é estreita a faixa de 
variação de valores: o isolamento encontrado se manteve entre aproximadamente 20 e $25 \mathrm{~dB}$, indicando baixa correlação entre as grandezas avaliadas.

Figura 4: Relação entre área da esquadria/área da parede e desempenho acústico. Fonte: Os autores.

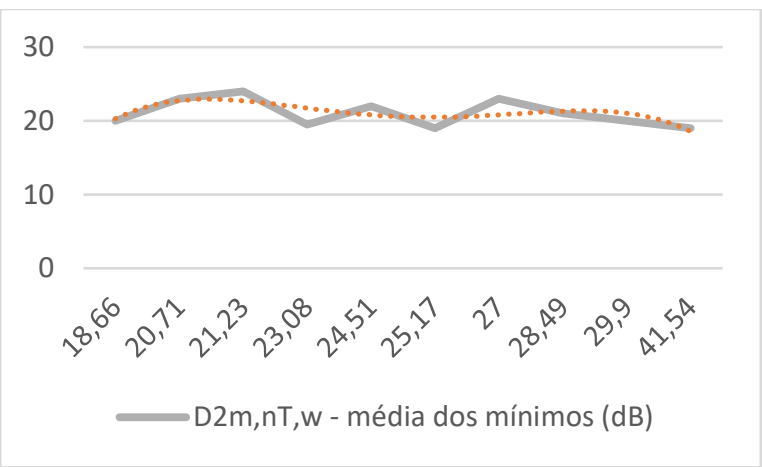

\section{Considerações Finais}

O presente artigo consta de uma breve avaliação do comportamento de vedações verticais de edifícios habitacionais no tocante à sua capacidade de bloquear a propagação de sons indesejáveis em seu interior.

Os baixos resultados referentes aos requisitos de desempenho citados na pesquisa e encontrados por meio das avaliações realizadas indicam que a norma de desempenho ainda não está sendo usada em nível esperado.

A relação entre tempo de reverberação e volume do ambiente encontrada apresentou dados de potencial importância para a otimização dos projetos de unidades habitacionais, no que se refere à concepção das áreas sociais, a fim de garantir espaço e conforto aos seus futuros usuários.

Alguns dos resultados encontrados mostram baixas relações entre as grandezas utilizadas para averiguação. Isso porque a heterogeneidade das amostras torna difícil a separação de apenas uma variável para análise. Resultados mais detalhados, além de uma amostragem maior, podem ser obtidos no caso de se prosseguir com a linha de pesquisa.

Vale salientar, no entanto, que os baixos desempenhos acústicos constatados não dependem apenas das grandezas avaliadas na pesquisa. Faz-se necessário também intensificar o aprimoramento tecnológico de materiais e serviços utilizados para a construção de edificações habitacionais, a fim de garantir a entrega de empreendimentos que disponham de alta qualidade e salubridade.

\section{Referências}

[1] L. Mattei. Desenvolvimento Brasileiro no início do Século XXI: Crescimento Econômico, Distribuição de Renda e Destruição Ambiental. 2012.

<https://br.boell.org/sites/default/files/download s/lauro_mattei.pdf>. Acesso em: 04 ago. 2016.

[2] A. Cury, C. Caoli. PIB do Brasil cai 3,8\% em 2015 e tem pior resultado em 25 anos. <http://g1.globo.com/economia/noticia/2016/03 /pib-do-brasil-cai-38-em-2015.html>. Acesso em: 13 nov. 2017.

[3] Associação Brasileira de Normas Técnicas ABNT. NBR 12179: Tratamento acústico em recintos fechados. Rio de Janeiro: ABNT, 1992.

[4] E. Fraga. Brasileiro tem pela $1^{a}$ vez poder de compra menor do que chinês. <http://www1.folha.uol.com.br/mercado/2017/0 8/1913381-brasileiro-tem-pela-1-vez-poder-decompra-menor-do-que-chines.shtml>. Acesso em: 13 nov. 2017.

[5] K. Z. Zhou, F. Wu. Technological capability, strategic flexibility, and product innovation. Strategic Management Journal, v.31, p. 547-556, 2010.

[6] R. P. Carvalho. Acústica Arquitetônica. Thesaurus, Brasília, 2006.

[7] A. P. Cardoso et al. Efeito da exposição prolongada a ruído ocupacional na função respiratória de trabalhadores da indústria têxtil. Revista Portuguesa de Pneumologia, [s.l.], v. 12, n. 1, p.45-60, 2006

[8] J. T. P. Martins. Acústica de Edifícios Validação experimental do cálculo de transmissões marginais a sons aéreos em edifícios. Dissertação de Mestrado. Unniversidade do Porto, 2008. 
[9] Associação Brasileira de Normas Técnicas ABNT. NBR 15575-4: Edificações habitacionais desempenho. Parte 4: sistemas de vedações verticais internas e externas. Rio de Janeiro: ABNT, 2013.

[10] Câmara Brasileira da Indústria da Construção. Desempenho de edificações habitacionais: guia orientativo para atendimento à norma ABNT NBR 15575/2013. Gadioli Cipolla Comunicação, Brasília, 2013.

[11] O. J. Silva Júnior, J. J. R. Silva, M. A. S. Pinheiro. Desempenho acústico de divisórias verticais em blocos de gesso: uma avaliação a partir de medições de campo e em laboratório. Parc Pesq. em Arquit. e Constr., [s.l.], v. 5, n. 2, p.1-7, 31 dez. 2015.

[12] R. C. T. Penedo; M. L. G. R. Oiticica. Isolamento sonoro aéreo de partições verticais de um apartamento em Maceió-AL Brasil. Parc Pesquisa em Arquitetura e Construção, [s.l.], v. 5, n. 2, p.7-14, 2014. Universidade Estadual de Campinas.

[13] A. C. Lordsleem Júnior. Melhores Práticas: Alvenaria de Vedação com Blocos de Concreto. Associação Brasileira de Cimento Portland, São Paulo, 2012. 72 p.

[14] D. V. P. Marques. Racionalização do processo construtivo de vedação vertical em alvenaria. Trabalho de Conclusão de Curso, UFRJ, 2013.

[15] M. H. F. de Medeiros. Vedações Verticais: Curitiba: Ufpr, 2013. <http://www.dcc.ufpr.br/mediawiki/images/5/5f/ TC025_Vedações_A_x.pdf >. Acesso em: 06 set. 2016.

[16] C. C. Schvarstzhaupt, B. F. Tutikian, M. F. O. Nunes. Análise comparativa do desempenho acústico de sistemas de fachada com esquadrias de PVC com persiana e diferentes tipos de vidros em ensaios de laboratório. Ambiente Construído, [s.I.], v. 14, n. 4, p.135-145, dez. 2014.

[17] J. B. S. Santos Neto et al. Innovation in the use of residual from the sugar-alcohol sector. Revista Gestão, Inovação e Tecnologias, [s.I.], v. 4, n. 5, p.1536-1549, 2014.
[18] F.R. Beltrame, Esquadrias para Edificações - Como atender a norma de desempenho das edificações ABNT NBR 15575 - 4. <http://www.afeal.com.br/portal/dados/imagens /1378234873.pdf>. Acesso em: 08 nov. 2016.

[19] D. Jones. Acoustical Noise Control. In: Handbook For Sound Engineers. Taylor \& Francis, Oxford, 2008.

[20] D. M. R. Mateus. Acústica de Edifícios e Controlo de Ruídos. Fctuc - Universidade de Coimbra, Coimbra, 2008. 84 p.

[21] D. Fauro, B. da Rocha; C. O. Pereira. A influência da forma no desempenho acústico dos ambientes. Sepe: Simpósio de Ensino, Pesquisa e Extensão, Santa Maria, 2011.

[22] International Organization for Standardization - ISO. ISO 140-4: Acoustics Measurement of sound insulation in buildings and of building elements. Part 4: Field measurements of airborne sound insulation between rooms. Switzerland: ISO, 1998.

[23] ISO 140-5: Acoustics Measurement of sound insulation in buildings and of building elements. Part 5: Field measurements of airborne sound insulation of façade elements and façades. Switzerland: ISO, 1998.

[24] ISO 16283-1: Acoustics -

Field measurement of sound insulation in buildings and of building elements. Switzerland: ISO, 2014. 